\title{
EM DEFESA DE UM CORPO-POTÊNCIA: NOTAS SOBRE EDUCAÇÃO E POLÍTICA
}

\author{
Ana Paula Parise Malavolta ${ }^{i}$ \\ Fernanda Monteiro Rigue ${ }^{\mathrm{ii}}$ \\ Camilla Baldicera Biazus ${ }^{\text {iii }}$
}

\begin{abstract}
Resumo: O presente texto é um convite para pensar possíveis percepções e enunciações sobre o corpo no campo da educação. Para tanto, nos aproximamos os escritos de Michel Foucault (1989), Gilles Deleuze e Félix Guattari (1995), Giorgio Agamben (2014 - 2017) e Baruch de Espinosa (1998) para construir um pensamento que nos permita atentar para uma vivência da corporeidade no contexto escolar, além das fronteiras da escola tradicionalmente estabelecida. A partir da potência política da costura, damos ênfase à Pedagogia crítico-performativa e às oficinas desenvolvidas pelo NAT, para alargar o leque de possibilidades de agenciamentos sobre o corpo no espaço educacional. Propomos, ao fim, problematizações que se apresentam por olhares outros em defesa de um corpo-potência, atentando para suas dimensões poéticas e performativas.
\end{abstract}

Palavras-chave: Corpo; Escolarização; Potência.

\section{IN DEFENSE OF A POWER BODY: NOTES ON EDUCATION AND POLITIC}

\begin{abstract}
This text is an invitation to think about possible perceptions and statements about the body in the field of education. To this end, we approach the writings of Michel Foucault (1989), Gilles Deleuze and Félix Guattari (1995), Giorgio Agamben (2014 - 2017) and Baruch de Espinosa (1998) to build a thought that allows us to pay attention to a corporeality experience. in the school context, beyond the boundaries of the traditionally established school. From the political power of sewing, we emphasize the Critical-Performative Pedagogy and the Workshops developed by NAT, to broaden the range of possibilities of agency on the body in the educational space. In the end, we propose problematizations that present themselves by looking at others in defense of a power-body, paying attention to its poetic and performative dimensions.
\end{abstract}

Keywords: Body; Schooling; Power.

\section{Palavras iniciais}

\footnotetext{
"Socorro não estou sentindo nada. Nem medo, nem calor, nem fogo. Não vai dar mais para chorar. Nem para rir. Já não sinto amor e nem dor. Já não sinto nada... Socorro, alguém me dê um coração, que esse já não bate nem apanha. Por favor, uma emoção pequena, qualquer coisa. Qualquer coisa que sinta. Tem tantos sentimentos, deve ter algum que sirva..." (Alice Ruiz e Arnaldo Antunes $\left.{ }^{4}\right)$.
}

2020 Malavolta; Rigue; Biazus Este é um artigo de acesso aberto distribuído sob os termos da Licença Creative Commons Atribuição Não Comercial-Compartilha Igual (CC BY-NC-4.0), que permite uso, distribuição e reprodução para fins não comerciais, com a citação dos autores e da fonte original e sob a mesma licença. 
A construção desse texto tem por intuito problematizar o corpo na educação escolar hoje, buscando superar a visão do corpo como ferramenta, como matéria passiva sujeita a intervenções. Esse movimento de investigação se justifica por acreditarmos que o corpo pode ser pensado de um modo distinto do que vem sendo tradicionalmente abordado em sistemas educacionais que ainda operam a partir de uma lógica disciplinar.

A nosso ver, uma educação significativa precisa permitir a emergência de um corpo enquanto potência, de um corpo-potência. Um corpo que ao invés de ser compreendido/visto em oposição à mente, passa a ser reconhecido como autônomo em relação a ela. Nesse sentido, de acordo com as ideias de Espinosa (1998), defendemos aqui uma relação de paralelismo entre corpo-mente e, não mais de um dualismo que parece aprisionar o corpo dentro dos espaços educacionais. Assim, o corpo-potência, em sua autonomia a paralelismo em relação à mente, a partir de seu modo de funcionar próprio, não pode mais ser colocado à serviço da mente, da produtividade do ambiente educacional, mas sim deve ser pensado como um território produtor de novas/outras realidades a serem aprendidas.

A epígrafe que abre este ensaio, busca através da música/poesia denunciar o esvaziamento da experiência/vivência dos corpos no âmbito das práticas educacionais. Corpos aprisionados e blindados das suas capacidades de sentir para atingir a máxima eficiência da mente, diminuindo com isso a sua potência de agir, de existir. Parece haver nesse espaço um sentimento de despertencimento, de desengajamento, de despossessão de si, de uma vida que passa a ser sentida como falsa justamente por ser vivida como reação e não como experimentação. Dessa forma, o sujeito acaba reagindo mais do que sendo e reivindicando ao outro determinações sobre o que sentir, sobre o que e como ser. Essas questões nos fazem pensar que a educação está sendo palco de encontros tristes, de afetos passivos, no sentido que nos traz Espinosa (1998). Por isso, através das reflexões construídas até então, desejamos retomar e resgatar a vivência da potência da vida dos corpos na/da educação, devolvendo ao ser sua condição genuína de afetar e ser afetado por outros corpos.

Para tanto, nos aproximamos dos escritos de Michel Foucault (1989) com seu texto Vigiar e Punir e a disciplinarização dos corpos; Gilles Deleuze e Félix Guattari (1995) e o Corpo sem órgãos; Giorgio Agamben (2014 - 2017) e a perspectiva das formas-de-vida e inoperosidade, bem como Baruch de Espinosa (1998) e sua potência dos afetos, para construir um pensamento que nos permita atentar para uma vivência significativa do corpo na educação. Todo o pensamento se inicia em uma experiência sensória/estética. Estética não mais restrita à 
doutrina do belo, mas referente às 'qualidades do nosso sentir', como tão bem descreve Freud em 1919, na sua obra "Das Unheimliche". Assim, as reflexões tecidas neste ensaio, partem de uma experiência estética que construímos, ao longo da escrita, com os autores, ilustrações/imagens e, também, com as habitações nos espaços educacionais, buscando permitir aos nossos corpos (trans)bordar no papel vivências enquanto sujeitos também atravessados pelas marcas da educação escolarizada.

O aporte teórico nos possibilita tecer nesta escrita um trabalho semelhante ao ato de costurar. Costuramos pensamentos, ideias, experiências, vivências, experimentações singulares. Por isso, para começarmos a tessitura nessa proposta que apresentamos, deixamos algumas potentes e poéticas palavras da artista Edith Derdyk:

Costurar supõe a condição de furar o material para logo depois juntar. De um tecido contínuo qualquer, de qualquer matéria maleável e flexível, passível de ser transpassada, será preciso furar, cutucar, romper, cortar para ligar este mesmo material numa outra configuração. Romper as malhas das tramas, das fibras encadeadas, das linhas sobrepostas, uma a uma, num determinado ritmo e velocidade para novamente religá-las, numa outra sucessão (DERDYK, 2010, s.p).

Com as palavras de Derdik materializamos o fazer e sentir, que permeiam essa escrita. O corpo e sua dimensão política são o foco desse manuscrito, na medida em que se busca retomar/(re)significar, ou quem sabe até mesmo transbordar, o lugar do corpo na educação escolar. Para além da sua relação com o pensamento, com a consciência, com a razão da mente que privilegia o desenvolvimento massante do campo intelectual do sujeito, pretendemos tomar o corpo como território existencial dos processos educacionais.

\section{Preparando-se para costurar: analisando tecidos e escolhendo linhas}

"Você precisa ir à escola para não ficar burro", "Você precisa estudar para ser alguém na vida". A educação e sua velha promessa e prospecção de um futuro e mundo melhor. Essas são narrativas que frequentemente crianças e adolescente escutam de seus pais, professores, familiares e amigos. Frases carregadas de expectativas, promessas, imposições que, naturalizadas, acabam, muitas vezes, contribuindo para a retirada do sujeito da cena escolar. 
No espaço da educação escolar não parece ser o sujeito quem fala, mas sim o outro que fala por esse sujeito, que decide, escolhe e exige. Isso nos faz pensar em questões que se fazem presentes no cenário atual da educação no país, tais como: a dificuldade cada vez maior de adaptação das crianças às escolas, o alto índice de evasão escolar, a dificuldade do aluno de se manter em sala de aula, alunos classificados como 'analfabetos funcionais' e a vivência de um esvaziamento de sentidos dentro do espaço educacional. O que está acontecendo com esses sujeitos que adentram a escola? O que esses sujeitos vêm denunciando, ou melhor, seria dizer, enunciando em nome próprio frente às suas vivências dentro de um sistema educacional? Será que estamos conseguindo ouvir esses sujeitos?

Retomando as frases que abrem nosso processo de costura, podemos pensar que antes do sujeito entrar na escola ele ocupa, perante a sociedade escolarizada, a posição de 'não saber', tendo em vista que precisa habitar o espaço institucionalizado de educação para que esteja 'habilitado' educacionalmente. É nessa contingência que se justifica a entrada do mesmo na escola, para 'ser alguém', para sair do 'não saber'. Nesse sentido, na maioria dos casos a escola é tomada como a detentora do saber, do conhecimento, das noções de verdade sobre a realidade e, o aluno, por sua vez, leva à escola o seu corpo-receptáculo, aquele que espera explicações e que sentado em fileiras passa a acreditar ser possível adquirir capacidades/habilidades que o dignifiquem/qualifiquem como ‘cidadão’ perante a sociedade.

Por sua vez, algumas questões tomam relevo quando atentamos para essas naturalizações que circundam a concepção de escola: E o que sujeito aprendeu correndo e brincando com os amigos na rua? Fazendo pipa e pescando com o pai? Desbravando o mato e cuidando dos animais com o avô? Ajudando a mãe nas atividades de casa? Aprendendo a fazer sabão com as tias aos domingos? Não seriam todas essas vivências e aprendizagens conhecimento? Onde ficam as memórias, as vivências quando o sujeito adentra no espaço formal da escola?

Historicamente, no contexto da escolarização ocidental, a noção da organização do corpo que frequenta a escola já foi sendo naturalizada com a mesma intensidade que as práticas escolares empreendidas nesses espaços. Conforme afirma Corrêa (2006):

A prática escolar já nos é familiar nos primeiros anos de nossas vidas - seja pelo incentivo familiar seja pela frequência ao maternal, à creche ou à escolinha - o que faz com que a pergunta "o que é escola?" não tenha mais sentido; já se sabe o que é a escola de um modo muito claro, pois já temos no corpo a compreensão de tudo que implica esta palavra: os horários, a 
disciplina, as recompensas e sanções, as leituras, os cálculos e, principalmente, um futuro. (p. 22).

Comumente pensamos que, frequentemente, as memórias, vivências e aprendizados que ocorrem fora do espaço escolar ficam soterrados pelo excesso de expectativas, normativas e imposições presentes na escola, devendo por isso serem apagados. $\mathrm{O}$ uso da primeira pessoa desqualifica o conhecimento desde quando entramos no espaço escolar. Para ter o estatuto de conhecimento científico o 'eu' dificilmente tem a chance de aparecer. Com base nas diferentes áreas do conhecimento, essas intensidades de apagamento variam, o que diz de um empenho de forças para que esses paradigmas se modifiquem. Por sua vez, não se pode esquecer que muitas vezes só nos é autorizado falar 'segundo fulano', 'de acordo com sicrano'. O 'eu' pouco pode pensar alguma coisa. Enganam-se aqueles que acreditam que só quando entramos nos espaços acadêmicos de Ensino Superior ou Pós-graduação perdemos a possibilidade de utilizarmos o pronome 'eu' em nossas escritas. O 'eu' é destituído de suas vivências muito antes da experiência de escrita acadêmica. Aprendemos, a partir das primeiras vivências dentro do espaço escolar, a apagar as marcas do eu, aquilo que diz das nossas histórias, memórias e potências.

Começamos a deixar o nosso 'eu' junto aos pais quando nos despedimos pela primeira vez ao pisar em uma escola. Isso se agrava ainda mais quando aprendemos a entregar nossas produções (artísticas/escritas) aos professores da Educação Infantil. Quando vemos essas mesmas produções retornarem com menções do tipo: Muito Bem; Continue assim; Tome cuidado, não pinte fora da margem. Essas menções aparecem como forças que vão constituindo modos de existência do ser.

Ao abandonarmos o 'eu' abandonamos também o corpo. O funcionamento da máquina que caracteriza o sistema escolar parece ser certeiro na produção da seguinte oposição: mente versus corpo. Tudo que é da ordem do corpo fica fora do espaço escolar ou restrito às práticas de Educação Física e ao ensino de Ciências Biológicas. Mas é preciso considerar que em ambas essas áreas, é dada a chance apenas de uma noção prioritária de corpo, o corpo da performance e o corpo anatômico-biológico, aquele construído cientificamente pelo campo da anatomia.

Assim, podemos pensar que historicamente a escola se deteve na fabricação de 'supostas' mentes brilhantes. Mentes gordas/obesas de 'cânones' e corpos fracos/raquíticos, privados de sua capacidade de sentir e experimentar: 
Figura 01 - Ilustração do Artista francês Dran.

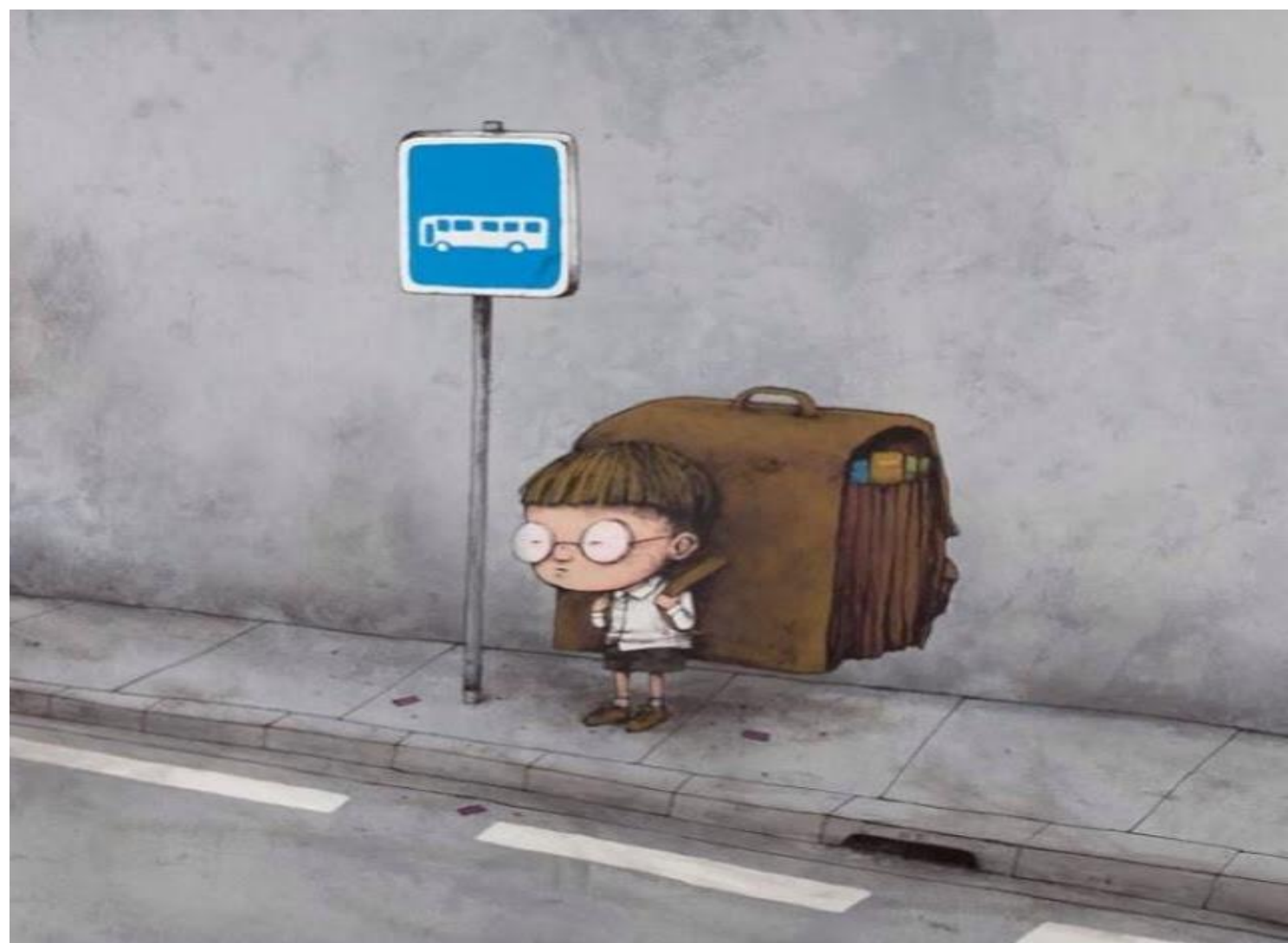

Fonte: https://florfofa.com/de-uma-olhada-na-arte-satirica-toda-a-franca/

A educação escolar, diz respeito a uma série de técnicas e estratégias que, em rede, se articulam para o desenvolvimento de um tipo específico de sujeito e sociedade, nos aproximando das ideias de Foucault (1989) sobre o poder disciplinar. Para o autor, o declínio da monarquia, no ocidente moderno, traz uma nova forma de poder que não opera mais pela coerção externa e sim, pelo próprio indivíduo. O poder se desloca então do soberano para a sociedade através do estabelecimento de normas e instituições que atuam no controle do sujeito. Dessa forma, a partir de técnicas de exercício de poder praticadas pelas instituições, o indivíduo e seu corpo são naturalizados e adestrados. Dentre as diversas instituições sociais estruturadas pelo poder disciplinar, Foucault (1989) cita a escola, nomeando-a também como 'casa da educação'. Assim a escola, de acordo com o autor, seria mais um espaço de vigilância constante sobre os corpos que ousam transgredir as normas por ela estabelecidas, assim como as demais instituições que demarcam território nesse espaço socialmente construído.

Corroborando com as ideias de Foucault (1989) sobre a sociedade do controle, citamos Passeti (2004): 
Na sociedade de controle, o corpo da população deixa de ser o alvo do Estado. Não se pretende mais dele extrair, pela disciplina, o máximo de energias econômicas para reduzir as forças políticas de resistências, esperando docilidades. Persegue-se a convocação à participação numa velocidade capaz de suprimir resistências, integrando a todos. Uma nova era de produtividade toma a dianteira e desloca-se para o interior do corpo, para os nervos, superando a mecânica industrial para afirmar a programática computacional. (p. 157)

Sociedade de controle que, [...] exige-se jovialidade, sorriso, bem-vestir, polimento, o elogio ao outro como forma de prestígio obtido e reconhecido, nivelamentos trazendo cada outro para próximo de si, humanitariamente (PASSETI, 2004, p. 157). Maquinaria que afeta diretamente o contexto educacional. Uma historicidade da escolarização, por exemplo, empreende uma série de esforços individuais e coletivos que permitem a emergência de uma série de arquivos que normatizam e orientam o funcionamento das escolas de Educação Básica e instituições em nível Superior.

Em meio a essa série de arquivos que materializam uma grande rede de instituições educativas estão todos os sujeitos que, de uma forma ou de outra, põe em movimento as perspectivas escolarizantes e delineamentos. Professores(as), estudantes, técnicos/gestores educacionais, bibliotecários, funcionários de serviços gerais, entre outros, são elementos que operam as engrenagens desse sistema. Muito além da identificação funcional desses sujeitos, é imprescindível considerar que um professor já foi estudante. Que técnicos/gestores educacionais, bibliotecários e funcionários também já foram estudantes. Mas o que eles têm em comum encontra-se muito aquém dessa consideração. Todos são feitos de carne e osso. Possuem um organismo biológico vivo que lhes permite existir. São sujeitos-corpo com particularidades e subjetividades. Independentemente de quais funções exerçam no campo de atuação que formaliza um universo profissional que permite a relação econômica-políticasocial, são corpos.

O corpo que habita a escola se insere em uma maquinaria pensada para pôr em prática conhecimentos específicos e pré-definidos. Nesse funcionamento está a postos uma série de conteúdos disciplinares (Física, Biologia, Matemática, Química, Português, Geografia, História, entre outros) que se articulam, na maioria das vezes em seriações, como estratégia para melhor estabelecimento de administração do 'bom' andamento das atividades com os estudantes. 
Em todas as instâncias põe-se em funcionamento corpo versus mente, afeto versus razão, dicotomias que empobrecem as vivências do humano dentro do espaço educacional. Como pensar em um, sem pensar, necessariamente, no outro? Como os processos de aprender e produzir conhecimento podem estar separados das vivências do corpo, de suas memórias, histórias, dos afetos que o constituem? Talvez seja justamente isso que o cenário educacional esteja tentando enunciar/denunciar em nome próprio: o corpo está adoecendo, está cansado, está perdendo o sentido de permanecer nesses espaços. Diante dessas reflexões iniciais e, nos remetendo à Espinosa (1998) para pensar o corpo, acreditamos ser importante lançar a seguinte pergunta: o que pode um corpo na cena escolar?

A [...] rotina pedagógica da escola desenvolve-se a partir do silêncio e do corpo estático. Sentado numa carteira de escola, por quatro horas diárias, olhando a parte de trás da cabeça do colega o corpo está parafusado (PREVE; CORRÊA, 2000, s/p). Ali, naquele espaço, o corpo parece não poder dar provas de que está presente, de que está vivo, ele precisa se anular, se permitir domesticar em prol de algo maior: a 'aquisição' do conhecimento e uma prospecção de futuro. Como se fosse possível adquirir algo de forma passiva, submissa. Aqui nos parece mais uma vez evidente a separação entre mente e corpo, tanto que se naturalizou/banalizou dentro dos espaços escolares a produção do diagnóstico de Transtorno do Déficit de Atenção com Hiperatividade (TDAH) e o uso de medicamentos como é o caso da ritalina. Ressoa nesses diagnósticos e práticas que é preciso fazer o corpo obedecer, parar, para que só assim seja possível pensar, raciocinar, responder questões, resolver exercícios, tornando o corpo dócil e receptivo às práticas e estratégias escolares.

Essas reflexões se aproximam dos pensamentos de Foucault acerca do entendimento de um corpo controlado e disciplinado, principalmente em sua obra Vigiar e Punir (1989), na qual o autor se preocupa em pensar as técnicas de disciplinarização do corpo ao longo da história. Nesse aspecto, Foucault contribui de maneira significativa para que fosse possível compreendermos o quanto o capitalismo produziu um olhar específico para produção de um corpo-máquina. É neste contexto que Foucault (1988) nomeia o biopoder, que integra-se a essas técnicas de disciplinarização dos corpos. O biopoder, para o autor, visa alcançar toda a espécie humana através de práticas/técnicas de poder sobre os processos biológicos, a fim de se apropriar do corpo para melhor manejá-lo. Assim, o biopoder torna-se essencial para o capitalismo uma vez que ao controlar a vida e os corpos desses sujeitos, acaba por adequá-los 
aos processos econômicos - reatualizando-se permanentemente. Corroborando com as ideias de Foucault, Castelo Branco (2015) discorre:

Quando a questão passou a ser o controle a correção das operações do corpo, entrou-se na era do homem instrumento, do homem objeto dos estudos que pretendem aperfeiçoar e tornar mais produtivo, no detalhe, o uso de seu corpo em ação na fábrica, na caserna, na prisão, etc. (p. 32).

Esse mesmo corpo prospectado pela sociedade capitalista foi capturado pelos ambientes escolarizados. Sob esse aspecto, com base nos estudos de Foucault (1989), o corpo é fabricado a partir do controle da individualidade dos sujeitos, sob a via da totalização. Nesse sentido, uma homogeneidade justificada pelo trabalho em nível macro da escolarização opera a partir da lógica da homogeneização, onde $O$ padrão privilegia e reproduz um determinado tipo de cultura, pois isso facilita a governabilidade dos corpos (SANTOS; CERVI, 2019, p. 08). Ao passo que esse mesmo corpo é também, nas palavras de Foucault (1989):

[...] a superfície de inscrição dos acontecimentos (enquanto a linguagem os marca e as ideias os dissolvem), lugar de dissociação do Eu (que supõe a quimera de uma unidade substancial), volume em perpétua pulverização (p. 22).

Dessa forma, Foucault pensa a escola como uma instituição disciplinar, que adestra os corpos, tornando-os dóceis e úteis à dominação. Essa é a estratégia biopolítica da/na educação escolar: controlar para dominar. E, por mais que nossas reflexões possibilitem nos aproximarmos e questionarmos o corpo do aluno nesses espaços, é importante não nos esquecermos que nenhum corpo fica imune às estratégias de controle da escolarização e do Estado.

Frente a isso, chamamos a atenção para o projeto de lei que ainda está tramitando no senado que se chama 'Escola sem partido' (PL 246/19). Esse projeto foi idealizado pelo advogado Miguel Nagib em 2014 com a justificativa de combater o posicionamento político, ideológico e de gênero feito por parte dos professores. Em 2018, o projeto foi arquivado, porém agora, em 2019, ele é retomado pela deputada Bia Kicis (PSL/DF). A maior mudança em relação ao antigo projeto se encontra no Art. $7^{\circ 5}$, o qual é citado a seguir: 


\section{O projeto de Miguel Nagib:}

Art. $7^{\circ}$. As escolas que não realizarem ou não disponibilizarem as gravações das aulas deverão assegurar aos estudantes o direito de gravá-las, a fim de permitir a melhor absorção do conteúdo ministrado e de viabilizar o pleno exercício do direito dos pais ou responsáveis de ter ciência do processo pedagógico e avaliar a qualidade dos serviços prestados pela escola.

O "novo" projeto da deputada Bia Kicis (PSL/DF):

Art. $7^{\circ}$ É assegurado aos estudantes o direito de gravar as aulas, a fim de permitir a melhor absorção do conteúdo ministrado e de viabilizar o pleno exercício do direito dos pais ou responsáveis de ter ciência do processo pedagógico e avaliar a qualidade dos serviços prestados pela escola.

A partir da breve exposição sobre o projeto 'Escola sem partido', é possível identificarmos o quanto o professor torna-se refém do aluno, caso ouse romper com a "suposta neutralidade" que lhe é exigida. O projeto busca "pregar" o fim da suposta "doutrinação ideológica", mas o que parece se esconder por trás da lei é a censura da liberdade de expressão nos ambientes escolares. O projeto "Escola sem partido" parece mobilizar a ideia de que o corpo, dentro da educação, precisa ser neutro, ahistórico, apolítico, apensante. Corpo amputado de suas marcas, de seus sentidos e sentires particulares. Não é sem motivos que um dos slogans da campanha que defende o projeto é Por uma lei contra o abuso da liberdade de ensinar ${ }^{6}$ :

Figura 02 - Charge feita por Mário, intitulada "Escola sem partido".

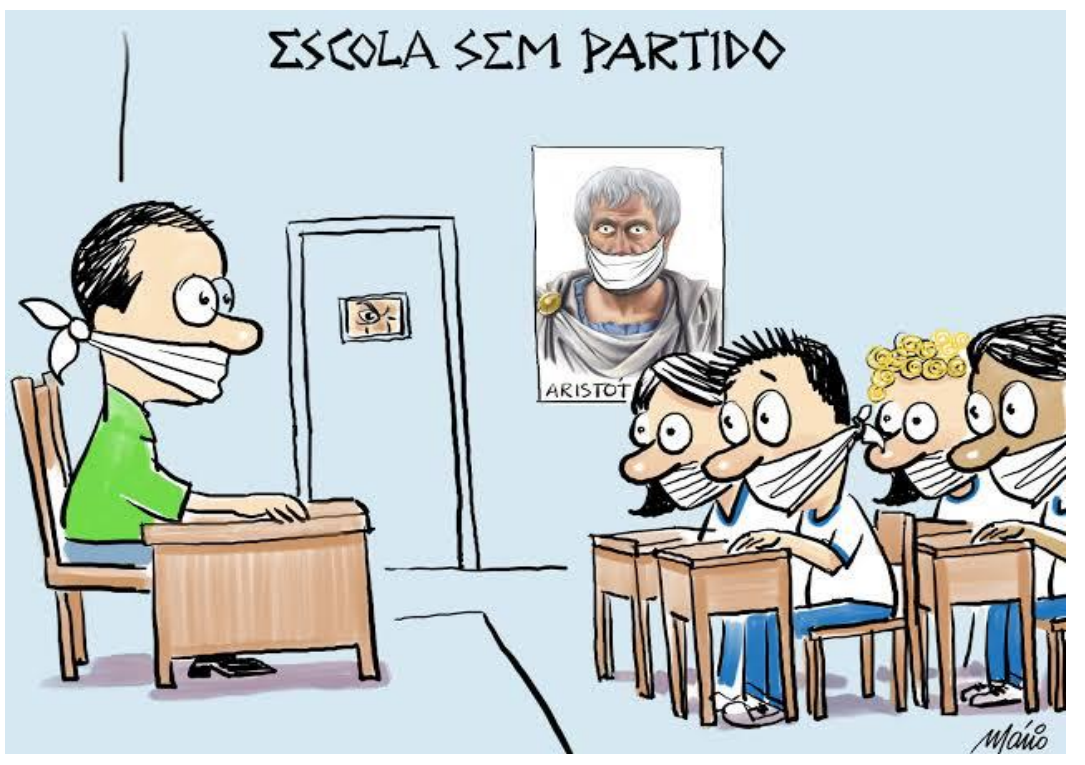

Fonte: https://florfofa.com/de-uma-olhada-na-arte-satirica-toda-a-franca/ 
Sendo assim, poderíamos dizer que, na perspectiva do projeto "Escola sem partido" ter liberdade, ou melhor, sentir-se livre dentro do espaço educacional é um abuso, é perigoso e, sendo assim, é necessário como já nos dizia Foucault, vigiar e punir. Frente a isso, nos perguntamos: Como é possível habitar um espaço sem poder exercer a presença dentro dele? Não seria passível de denúncia esse impedimento da ordem da violência, do abuso? Não iremos nos deter aqui em maiores discussões acerca do referido projeto, mesmo sabendo da importância de refletirmos sobre os impactos desse movimento para a educação. Contudo, queremos a partir desse lugar, chamar a atenção para o perigo que o corpo parece representar no cenário da escolarização, tendo que para tanto formularem projetos de lei que autorizam a denúncia e a punição àqueles corpos que ousam se manifestar para além dos conteúdos curriculares determinados por quem tem o poder de decisão, de estabelecer conteúdos e planos disciplinares mais ou menos importantes para crianças e jovens.

Corpos fabricados. Controlados, desvitalizados. Corpos precedidos pelas letra a (ahistórico, apolítico, apensante) como forma de barrar o movimento potência, de imobilizar o pensar e o corpo. É desse lugar que se dá o funcionamento da maquinaria escolar e, problematizá-lo como chance de romper com ele, é o nosso desafio:

Figura 03 - Ilustração da artista italiana Elia Colombo.

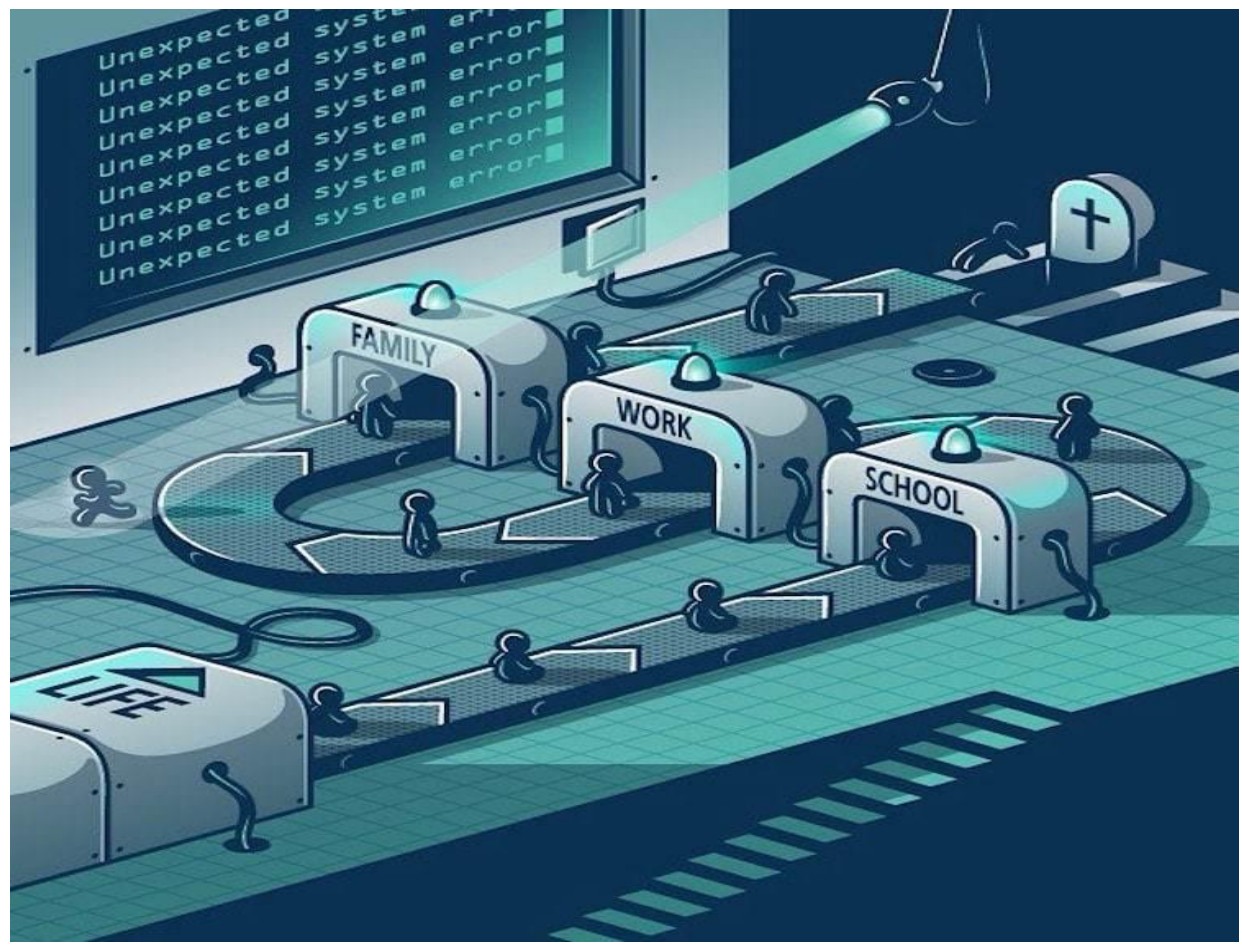

Fonte: https://theblog.adobe.com/the-creative-contemplation-of-elia-colombo/ 
A escola relaciona o processo de ensino e de aprendizagem a duas práticas, interdependentes: a assimilação de conteúdos e a imobilização do corpo na carteira escolar. Ambas atuam dificultando a construção de um pensamento em primeira pessoa, pois o conhecimento ensinado já está cientificamente, já está dado, basta apenas adquiri-lo. A imobilização presente no espaço escolar é descrita por Corrêa e Preve (2011) como uma,

[...] ação que quer retificar e conter o inédito de cada vida em favor da proliferação de mensagens e da eliminação do silêncio, do vazio que suscita a atualização de forças de invenção; não é, no entanto, imobilidade - esse limite inatingível e sequer desejável pelas táticas de governo - é, antes, ação na busca de um equilíbrio ideal entre o que é permitido e o que não é; de conter o possível numa espécie de coreografia dos movimentos do corpo e do pensamento (p. 184).

Desse ponto de vista o professor controla e vigia o corpo do aluno ao mesmo tempo em que passa a ter também o seu corpo observado e controlado pelo próprio aluno e pelo Estado. O encarceramento está montado, ninguém fica de fora da visão do controle, das rédeas da dominação, tanto professor quanto aluno. Os corpos estão devidamente domados pelo olhar que imobiliza.

Dessa forma, não é mais o corpo como um inteiro que aprende, mas apenas partes dele. Diferentemente do que acontecia nas brincadeiras na rua, nos momentos compartilhados com outras pessoas, fora da escola, onde o corpo era convocado a estar presente; na escola, é a audição, o braço, a mão e limitadamente a boca que são ativadas para a 'aquisição do conhecimento' (PREVE; CORRÊA, 2000). Aquisição que passa pelo interesse em formar um cidadão,

Através do conjunto de regulamentos escolares e das suas práticas diárias, entra em ação um projeto político com caráter científico - com suporte nas legislações para a educação nacional e nas ciências da educação - pra direcionar as operações do corpo. E, nesse tempo escolar, o corpo entra em formação. Não interessa aqui o corpo único, singular, de cada um que utilize as suas potencialidades, mas o corpo do cidadão, do profissional assalariado, do consumidor. Haverá máquina mais presente, intensa e insistente, capaz de fazer o corpo chegar, por meio de exercícios constantes, a um ponto zero criação? (PREVE E CORRÊA, 2000, s/p).

A partir do pensamento movido pelos autores, a resposta para a nossa pergunta 'o que pode um corpo dentro da cena escolar?' parece configurar-se da seguinte maneira: o corpo pode 


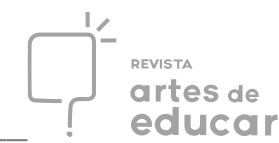

o que a escolarização e o Estado desejarem e, assim, permitirem. Corpos dóceis, úteis, imóveis, vazios a espera de preenchimento da mente, diretrizes que lhe digam o que ser e como ser enquanto sujeito. Não é sem motivos, que a hora do recreio ou do intervalo é vivida por alunos e professores como um momento de libertação, de soltar os 'monstros', de correr e gritar em busca de ser quem se é.

Mas o que aprisiona esse corpo? As disciplinas, a grade curricular, o livro didático, a exigência de passar horas sentado na mesma posição? Frente aos questionamentos, a consideração de SANTOS (2019) é pertinente, pois,

Se a escola funciona de modo similar a uma máquina podemos supor que há "engrenagens" em funcionamento para movimentar sua linha de produção, manufaturar a matéria prima e transformá-la no produto desejado. Na maquinaria escolar essa engrenagem é o currículo que é pensado e estruturado para produzir corpos e comportamentos alinhados aos padrões normativos socialmente estabelecidos e prestigiados. Para garantir que a maquinaria escolar produza adequadamente, vigiam-se corpos, gestos, falas e condutas de estudantes e professores (p. 06).

Acreditamos que a composição dos diversos fatores até então refletidos, contribuem para o condicionamento e encarceramento dos corpos de professores e alunos nos espaços escolares. É desse lugar que queremos a partir de agora convidar o corpo receptáculo, dócil e aprisionado a se permitir tornar um corpo potência, se abrindo à possibilidade de outros territórios existenciais dentro da educação, pois conforme nos diz Preve e Corrêa (2000),

Se é o corpo o lugar em que as forças massificadoras forjam uma subjetividade de massa, é dele também que depende a criação de modos de vida até agora nunca experimentados. O corpo que obedece é o mesmo que conspira e cria $(\mathrm{s} / \mathrm{p})$.

\section{Operando com as ferramentas: alinhavando a costura}

Após termos nos preparado para costurar, compondo nossa caixa de costura, aproximamo-nos de Giorgio Agamben (2014). O referido autor apresenta uma convergência ao pensamento produzido por Foucault, quando defende o pensar da potência por meio da criação de forças que possam reconstruir dispositivos biopolíticos de controle. AGAMBEN (2014) toma conhecimento do conceito de dispositivo em Foucault, oriundo da relação entre rede, 
estratégia, poder e saber, mas toma a liberdade de estendê-lo um pouco mais, incluindo a sua própria contribuição. Em Agamben (2014), dispositivo significa:

\begin{abstract}
Qualquer coisa que tenha de qualquer modo a capacidade de capturar, orientar, determinar, interceptar, modelar, controlar, e assegurar os gestos, as condutas, as opiniões e os discursos dos seres viventes. Não apenas as prisões, os manicômios, o Panóptico, as escolas, a confissão, as fábricas, as disciplinas, as medidas jurídicas etc., nas quais a conexão com o poder é em certo sentido evidente, mas também a caneta, a escritura, a literatura, a filosofia, a agricultura, o cigarro, a navegação, os computadores, os telefones celulares e - porque não- a linguagem mesma, que é talvez o mais antigo dos dispositivos, no qual há milhares e milhares de anos um primata - provavelmente sem perceber as consequências para as quais ia ao encontro - teve a inconsciência de fazer-se capturar (p. 39).
\end{abstract}

Com o conceito de dispositivo, defendido por Agamben (2014), percebe-se um núcleo, uma sinalização para uma tentativa de diagnóstico como possibilidade de pensarmos a política e a educação em nossos dias sem os dispositivos que a determinam, influenciam, manipulam. Para tanto, Agamben (2014) aponta para a direção de que devemos permanentemente tornar inoperosos os dispositivos de controle atuantes na sociedade.

Ainda na visão de Agamben (2014) faz-se necessário perceber cada vez mais uma influência do campo econômico sobre o campo educacional, jurídico e o político, onde [no qual] o poder assume uma posição cada vez mais de destaque nas decisões e direção da economia de governo. Essa hegemonia do interesse econômico em sobreposição aos políticos e educacionais, reduz a vida democrática ao mínimo necessário e as decisões políticas fundamentais são direcionadas pelo mercado, sem a consulta ou anuência mínima da vontade popular (AGAMBEN, 2014).

Nesta linha de enunciação, percebemos que a possibilidade da inoperosidade está profundamente imbricada na forma de vida que determina a potência do corpo que está vivendo. Todos vivem a sua vida, mas nem todos a vivem como se fosse uma 'forma de vida'. Sobre a constituição de uma 'forma de vida' AGAMBEN (2017), nos fala sobre uma forma de vida que [...] não pode ser separada da sua forma, uma vida para qual, em seu modo de viver, está em jogo o seu próprio viver e, no seu viver, está em jogo antes de tudo o seu modo de viver (p. 1314). Então, a constituição de uma "forma de vida" se dá no momento em que os dispositivos são desativados, e a potência se torna uma forma de vida, e, esta ao mesmo tempo em que se transforma em uma forma de vida, igualmente torna-se destituinte, fazendo inoperosas todas as formas singulares de vida. 
No campo da educação a inoperosidade pode se relacionar aos operadores metafísicos da antropogênese que, liberando o vivente homem do seu destino biológico ou social, o consigna àquela indefinível dimensão que estamos habituados a chamar de política. O político não é nem uma bios, nem uma zoé, mas a dimensão em que a inoperosidade desativando as práticas linguísticas e corpóreas, materiais e imateriais, incessantemente abre e remete ao vivente (AGAMBEN, 2014).

Nesse processo de destituir para fazer viver o vivente, percebe-se que, se defendermos caminhos para a educação se produzir como uma "forma de vida", estaríamos construindo estradas que levam ao movimento de relações de "corpos-potentes", em exercício permanente de liberdade, pois tornaria inoperosas as obras e funções específicas de cada ser humano, com seus destinos predeterminados, quer estes biológicos ou sociais (de ordem meritocrática, por exemplo).

Acreditamos que a mobilização da corporeidade é umas das problemáticas centrais não só na esfera da educação, mas no contexto das mais variadas ciências e campos epistemológicos, pois o existir humano se dá através do corpo - o corpo é o meio pelo qual nos utilizamos para experimentar o mundo, para existir no mundo. O ser humano é presença no tempo e no espaço como corpo. Nesse contexto, torna-se importante ressaltar Antonin Artaud (1896-1948) - poeta, dramaturgo e ator francês - responsável por cunhar primeiramente o termo 'corpo sem órgãos' ( $\mathrm{CsO}$ ), o qual em suas considerações seria uma espécie de anti conceito, que simbolizaria um corpo fragmentado e reorganizado de acordo com critérios não absolutos e em constante transformação. Este conceito nos apresenta possibilidade política de construção de um pensamento para além da concepção de um corpo biológico disciplinado e controlado, que se faz hegemonia na escolarização. O corpo sem órgãos se aproxima de uma prática política de performatividade e resistência no momento contemporâneo.

O CsO para Deleuze e Guatarri (1995) estaria marcado pela produção do real, no aqui e agora do acontecimento, movido pelas contingências da carne, através da quebra com a representatividade da vida, passando para a vivência do presente da vida. Este corpo escaparia de definições sobre si próprio, abrindo-se para movimentos involuntários que respondem às reações que lhe são impostas, fazendo-se, assim, vulnerável e potente na sua relação com o desconhecido que é o próprio corpo.

Então, para Deleuze e Guattari (1995), o CsO trata de um corpo fluído por onde passam as forças que promovem as ações. Um corpo marcado pelo signo da ausência, mas pleno de 
vida; uma vez que vida é ação, atividade. Neste sentido, o CsO é o lugar vazio, a presença e a ausência. As intensidades que constituem o $\mathrm{CsO}$ são tamanhas que expulsam todo e qualquer significado fazendo do corpo um lugar de passagem. Neste corpo, resta sempre o vazio a ser preenchido pelas potências, pelas forças.

Nesse caminho, o CsO é o lugar da experimentação, do devir. É o rompimento com qualquer passado ou valor que se imponha tentando imobilizar a potência criativa da existência. Diante do entendimento do $\mathrm{CsO}$, podemos ressaltar um corpo político, porque esse corpo parece se expressar por meio de uma dimensão provocativa de ondas de intensidades que disparam ações, sensações e comportamentos inventivos.

Nesse sentido, o Corpo sem Órgãos é o limite imanente interno do desejo. Ele se confunde com a morte para aqueles que estão apaixonados por seu pequeno organismo. A fluidez do $\mathrm{CsO}$ provoca o desacoplamento das máquina, pois ele desarranja, produz morte. $\mathrm{O}$ $\mathrm{CsO}$ impede que as máquinas desejantes se fechem em um arranjo local. Ela faz funcionar desarranjando. Desse modo, o $\mathrm{CsO}$ é o corpo pleno que permanece aberto às intensidades, é nele que devemos habitar para criar para nós mesmos um corpo potência. É sobre sua superfície móvel que encontramos a diferença, saltitando, se fazendo, aparecendo, se diferenciando em si mesma. Ele é o espaço para o indeterminado. É a linha que desvia de sua produção mecânica e previsível; é um corpo que se efetua pelo acontecimento, pelo inesperado, mobilizando-se na potência de sua performatividade (DELEUZE e GUATTARI, 1995) .

Todavia, é nesse sentido, que defendemos uma possibilidade de um 'corpo político educacional', aberto à invenção e a performatividade. Escrevemos na defesa de um corpo que possa apresentar maneiras de intensificação e articulação das potencialidades da vida como meio de inscrição e disseminação de relações humanas, como o liame de onde o sentido parte, faz fronteira, transgride, partilha, colide, compõe com outros corpos. É impossível duvidar de que chegamos ao mundo com um corpo, uma vez que o corpo se impõe segundo uma realidade concreta em sua espessura massiva, como uma forma viva que se move e se manifesta em sua existência. Nossas práticas e nossas técnicas implicam gestos, posturas e movimentos nas interações que estabelecemos com outros corpos, objetos e pessoas.

Sob esse ponto de vista, é possível pensarmos em um corpo-potência em educação?

Repetimos nossos hábitos todos os dias. Tomar um banho é um exemplo. No entanto, podemos nos colocar em modo automático e seguir o fluxo de uma vida funcional sem experimentar o seu sabor ou sem apreciar as suas águas. Uma questão intuitiva nos introduz um problema: ela diz que se as águas do 
nosso corpo estiverem muito agitadas, se os nossos pensamentos estiverem muito rápidos, então a experiência de um simples banho não será possível. Talvez possamos ampliar esse exemplo do banho para qualquer outra experiência e a qualquer um. Parece óbvio, mas as agitações giram o mundo cada vez mais rápido, com tantas coordenadas semióticas, fora ou dentro de nossas cabeças, numa pervasão audiovisual e a todo instante, que logo passamos a viver pelas urgências. Urgências que se inscrevem em nossos corpos, fazendo disparar velocidades de que não necessitamos. Portanto, durar em uma simples experiência pode ser um ato de resistência (PACHECO et. al., 2018, p. 230).

Com base na reflexão construída por PACHECO et. al. (2018), acerca das urgências que se tornam hábitos e se inscrevem nos corpos, é que propomos a possibilidade de pensar um Corpo-potência. Tencionamos a possibilidade de produzir outras enunciações sobre o corpo no âmbito educacional. Para isso, chamaremos para nossas proposições Baruch de Espinosa. Lembremos com CHAUÍ (1995), que por essência, o corpo espinosiano é constituído por relações internas e externas com outros corpos e por afecções, ou seja, pela capacidade de afetar outros corpos e de ser afetado por eles sem se destruir, o corpo se regenera com eles, assim como lhes dá uma maior capacidade vital.

Essa atividade do corpo de emancipar aos afetos que se mobilizam entre os demais corpos é uma característica constituinte de nosso Conatus. O Conatus, para Espinosa (1988), é o movimento espontâneo intrínseco a todo indivíduo e sua potência vinda da substância da vida; uma pulsação, pulsão originária de vida e de expansão, que leva todo indivíduo a buscar expandir sua potência.

Ademais, Espinosa (1988) afirma que o corpo precisa de uma alimentação variada e de exercícios diversos para estar plenamente apto a cumprir tudo o que concerne à sua natureza. Ele não deve se restringir apenas à repetição das mesmas atividades, haja visto que, neste caso, o desenvolvimento de suas aptidões seria desigual, conduziria à hipertrofia de algumas de suas partes em detrimento do todo, o que se faria acompanhar de uma atrofia mental em função da exposição excessiva a ideias fixas ou afetos renitentes (JAQUET, 2004, p. 20). Nestes termos, a igualdade entre a potência de agir do corpo e a potência de pensar da mente manifesta, antes de tudo, uma igualdade de aptidões para exprimir toda a diversidade e também diferença contida na natureza de cada indivíduo.

De acordo com CHAUÍ (2006), a vida humana instaura-se pela união de um corpo e uma mente, pois os seres humanos não são substâncias criadas e sim modos finitos da substância constituídos por modificações da extensão e do pensamento, isto é, são efeitos imanentes da 
atividade dos atributos substanciais. Nesse viés, CHAUÍ (2006, p. 119), amparada nas prospecções espinosianas, também nos diz que um corpo "é um modo finito do atributo de extensão constituído por uma diversidade e pluralidade de corpúsculos duros, moles e fluidos relacionados entre si pela harmonia e equilíbrio de suas proporções de movimento e repouso". Assim, entendemos que o corpo se efetua como uma singularidade, isto é, uma unidade estruturada: não é um agregado de partes nem uma máquina de movimentos, mas um organismo, ou unidade de conjunto, e equilíbrio de ações internas interligadas por órgãos. O corpo é um indivíduo, pois, como explica ESPINOSA (1988), quando um conjunto de partes interligadas agem em conjunto e simultaneamente como uma causa única para produzir um determinado efeito, essa unidade de ação constitui uma individualidade.

Sobretudo, o corpo apresenta um indivíduo dinâmico, pois o equilíbrio interno é obtido por mudanças internas contínuas e por relações externas contínuas, formando um sistema de ações e reações centrípeto e centrífugo, constituído por relações internas entre seus órgãos, por relações externas com outros corpos e por afecções, isto é, pela capacidade de afetar outros corpos e ser por eles afetado sem se destruir, regenerando-se com eles e os regenerando. Um corpo é uma união de corpos (unio corporum) e essa união não é um ajuntamento mecânico de partes e sim a unidade dinâmica de uma ação comum dos constituintes (CHAUÍ, 2006).

Neste terreno podemos tecer possibilidades de percepções acerca dos desdobramentos dos acontecimentos no corpo, ou seja, é possível sentir o corpo como ele realmente existe. No entanto, o conhecimento e a percepção deste corpo somente são possíveis através da mente. Por conseguinte, a mente está internamente ligada ao seu objeto, a saber, o corpo, visto que ela tem como função pensá-lo, e como o próprio Espinosa (1988, p. 65) define e demonstra: "a mente é a ideia do corpo". Todavia, no campo dos processos de escolarização, sabemos que corpomente culturalmente são vistos enquanto elementos distintos, como se o intelecto de um estudante pudesse ser preenchido de conteúdos e normativas disciplinares, enquanto o corpo que habita este intelecto não necessita da mesma potência de investimento. Nessa prospecção, conseguimos problematizar as práticas educacionais fragmentadas, dicotômicas e biopolíticas, no que se refere a percepção dos modos de ser e se apresentar no mundo de uma singularidade.

Desta forma, utilizaremos, neste momento, o exemplo da relação entre a abelha e a orquídea, que DELEUZE (1996) gosta de tomar para descrever o que pode ser um encontro aberto entre corpos, auxiliando-nos na problematização de um corpo-potência para educação. 


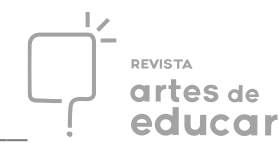

O encontro entre a abelha e a orquídea assemelha-se a um agenciamento de corpos, criando uma máquina única, através de uma dupla captura, do bicho pela flor e da flor pelo bicho.

Não tira-se mais uma estrutura comum de elementos quaisquer, espalha-se um evento, contra-efetua-se um acontecimento que corta diferentes corpos e efetua-se em diversas estruturas (DELEUZE; PARNET, 1996, p. 82).

Com esse pensamento, é possível refletirmos que a vivência constante do encontro de corpos em escolas, universidades, faculdades, instituições de ensino, apresentam relações potentes de afetos e capturas de relações, como é o caso da abelha e da flor. Desse modo, pensar na condição de abertura e encontro entre os corpos nos espaços educacionais, envolve a percepção sensível, como um processo de registro e captura de histórias, gestos e movimentos. Entendendo a captura não como síntese, mas como invenção de 'outra coisa', onde estão conectados corpos, ideias e energias habitualmente soltas. Nesse espaço há conexão de corpos por meio de suas potências de vida.

\section{Devires costureiros: fios para pensar corpo(s)}

Tendo como base o esforço até aqui apresentado para pensar o corpo-potência, agora trataremos de tencionar as possibilidades e/ou experiências que, de uma forma ou de outra, preocupam-se com uma noção de corpo enquanto possibilidade de existência na educação. As quais, de alguma forma, afetam modos distintos de pensar o conhecimento, alargando a compreensão das possibilidades em educação.

Uma dessas possibilidades é a Pedagogia crítico-performativa, que, para Marcelo de Andrade Pereira (2017, p. 34) consiste em uma poética educacional, catalogada, pela presentificação de conteúdos socioculturais, que se realiza por meio da potência artística, especificamente pela performance e/ou ações performativas, por sujeitos em processos formativos. Ademais,

[...] não se pode pensar a performance e, por conseguinte, a Pedagogia critico-performativa sem a presença do corpo e sua dimensão expressiva. $\mathrm{O}$ expressivo, aqui, refere-se a algo mais abrangente que o artístico, dizendo respeito à possibilidade de tornar visível, por meio de uma teoria/prática pedagógica peculiar, formas de aparição do sujeito que não são necessariamente acolhidas — e, por vezes, teoricamente não passíveis de 
serem acolhidas — no âmbito do comum. É preciso, assim, perguntar, no curso desta investigação, sobre o que constitui um comum e o próprio que dele participa (PEREIRA, 2017, p. 35).

Logo, essa pedagogia, por apresentar-se por meio de uma proposta performativa e inventiva, possibilita processos de desestabilização de discursos e normativas curriculares instituídas nos espaços educacionais, trazendo o corpo como elemento imprescindível da cena educacional. Esse modo crítico e performático agencia, no âmbito coletivo comum, gestos e ações de resistência de corpos, histórias e vidas, que partilham entre si sentidos e vivências diversas. Além disso, problematiza a potência do movimento e entrega do corpo diante do fazer docente e discente, apontando para a necessidade de um pensamento outro, sobre o processo educacional, não mais pautado por códigos e normas, mas sim, pela potência do encontro de singularidades distintas, que se propõe estarem juntos em um espaço comum, compartilhando e sentindo histórias, experiência, saberes e teorias.

A relação entre performance e Educação nos possibilita refletir para além do contorno de saberes e conhecimentos, determinando um modo de organização amparada pela experiência coletiva. Nesse viés, performance é experiência, ação, intervenção e nos permite " [...] pensar a própria prática educativa como invenção” (ICLE, 2013, p. 20).

Podemos pensar que a prática da pedagogia crítico-performativa no âmbito do espaço escolar e dos processos de ensino-aprendizagem, se apresentaria como uma metodologia ativa, política e problematizadora. Estaríamos neste sentido, propondo uma relação atuante e partilhada entre professores e alunos, baseada na performatividade subjetiva de cada um. Nesse viés, processos de experimentações e vivências significantes podem acontecer pela possibilidade de transformação dos modos de ensinar e aprender, uma vez, que o conhecimento pode ser compartilhado no encontro potente entre corpos diversos, que trazem consigo histórias, territórios e linguagens específicas.

Uma vez pautada pelos movimentos singulares, políticos e performáticos a Pedagogia crítico-performativa encontra-se como que enleada a um processo de materialização de sentidos, dados e produzidos de maneira singular, a partir do qual se constitui um próprio, em um âmbito comum, como diferença e também semelhança, no decurso da ação educativa; se fazer presença no espaço educacional, pode significar então, a possibilidade de tornar algo visível, "tornar um próprio, qualquer, passível de ocupar um lugar no espaço do comum" (PEREIRA, 2017, p. 31). Nessa perspectiva, a escola se estabeleceria como um espaço 
multirreferencial do comum, direcionando olhares e saberes a partir da diversidade. Assim, seria possível relacionar propostas curriculares à meios significativos de aprendizagem, na medida mesma, que aproximaria a escola, os conteúdos, os corpos, as singularidades do mundo em que vivemos, com todas suas incertezas, problemáticas e narrativas.

Neste ínterim, como possibilidade de exemplificação, tem-se o empenho desenvolvido pelo Núcleo de Alfabetização Técnica (NAT) do Centro de Ciências da Educação (CED) da Universidade Federal de Santa Catarina (UFSC). O NAT tem um longo percurso histórico de desenvolvimento do trabalho com as Oficinas que pensam o corpo de modo amplo e significativo.

As Oficinas possuem uma perspectiva não disciplinar, tendo em vista que Oficina é essencialmente trabalho diversificado com prazer, e não pode ser reduzida à sucessão de tarefas rotineiras que caracteriza o chamado trabalho escolar (OLY PEY, 1997, p. 47). Desse modo, o trabalho das Oficinas [...] rompe com a organização curricular disciplinar dos conteúdos (OLY PEY, 1997, p. 47), ao mesmo tempo em que não exige idades, sexos, escolaridade ou pré requisito de conhecimento para que as pessoas possam participar (OLY PEY, 1997).

A construção das Oficinas tem perspectivas teóricas disparadoras. Segundo Oly Pey (1997), uma das principais idealizadoras das Oficinas,

A teoria ou, mais propriamente, os filósofos cujos pensamentos referendam a construção e o desenvolvimento das oficinas, nunca foram considerados como ponto de partida para a criação das mesmas. Ela é fruto do metabolismo entre um trabalho, uma prática sendo desenvolvida e a exigência de um referencial com o qual se possa estabelecer um diálogo. As três perspectivas que aparecem nesse mapa referencial são as seguintes: concepção libertária da educação, abordagem não disciplinar do processo educativo, relações dialógicas no ato de conhecer em interação (p. 45).

Desse modo, pensando acerca do que sejam Oficinas, Oly Pey (1997) escreve que:

[...] é possível já caracterizar elementos de sua caracterização: • projetos vivenciais, onde a dialogicidade é essencial na relação entre as pessoas. é desse tipo de relação dialógica que se obtém uma força coletiva de produção de saber superior que a soma das forças individuais; • que produzem saberes em autorias e obras. na produção da oficina não se parte da reprodução do conhecimento, mas da produção de um saber de resistência aos saberes disciplinares, transmitidos nas instituições formais de ensino. o estímulo à realização de atos poderes, e a liberdade, para o desejo tomar a direção que insistir, permite às pessoas desenvolver trabalho de investigação de saberes, ao invés de tarefas rotineiras; - que se articulam no âmbito dos saberes 
práticos, tecnológicos, científicos, artísticos, artesanais, intuitivos, literários e outros, sem colocar qualquer ordem hierárquica no trato deles. isso significa que acaba não havendo a parcialidade dos saberes impropriamente designados pela pedagogia como universais utilizados na programação das disciplinas curriculares (p. 47-48).

Desse modo, o trabalho com as Oficinas também se inspira no conceito de Alfabetização Técnica de Maurice Bazin, o qual permite uma maior autonomia para pensar os conhecimentos científicos por meio dos oficineiros.

A partir dessa atenção para o trabalho com as Oficinas desenvolvido pelo NAT, é possível considerá-lo como um modo singular de pensar o corpo no espaço escolar. No sentido que a Oficina [...] não cabe nos ritmos e rotinas temporais da educação formal (OLY PEY, 1997, p. 46-47), porque respeita os tempos e desdobramentos do coletivo de oficineiros, sem julgamentos e avaliações posteriores.

É nessa instância que o trabalho com as Oficinas se distancia das premissas escolarizadoras de pensamento do corpo. Nas oficinas, o corpo não se encontra encarceirado/aprisionado, pois é a partir das forças moventes que emergem do corpo dos sujeitos que ela pode acontecer. Em virtude disso, os limites escolarizados não adentram ao trabalho das Oficinas no NAT, no sentido que a potencialidade dos quereres dos oficineiros só acontecem quando o corpo quer com vontade aprender algo, se tornar parte, elemento chave para conhecer algo no trabalho coletivo.

Com isso, podemos considerar que a Pedagogia crítico-performativa e o trabalho desenvolvido pelo NAT acerca das Oficinas, são horizontes de possibilidades para pensar o corpo na educação. Para além de um corpo capturado pelas técnicas de disciplinarização, o corpo nessas duas possibilidades pensa o conhecimento como potência, como disparador para uma aprendizagem que afete o movimento, o querer com vontade.

Sabemos que Há muito trabalho a fazer, procurando e desfazendo os nós que barram os fluxos e impedem as invenções estéticas na vida. Provocar os corpos sem álibis e fazê-los ressoar (PACHECO et. al., 2018, p. 233). É nesse tom, nessa perspectiva que pensamos ser possível pensar em um Corpo-potência na educação. Em um corpo que sinta, viva, ressoe, onde A vida na dimensão ético-estética é o trabalho cotidiano e micropolítico de constituir um corpo capaz de suas intensidades (PACHECO et. al., 2018, p. 233). 


\section{Continuar a costurar}

O empenho aqui depositado para pensar o corpo na educação escolar, nos permitiu atentar para práticas educacionais que se distanciam do aprisionamento do corpo e da mente. Um corpo-potência é possível quando práticas educacionais se aventuram a tencionar espaços outros de educação. Não buscamos aqui propor novos meios para projetos educacionais, mas, de um modo geral, podemos dizer que apontamos percursos teóricos e práticos, que podem produzir movimentos de reação/resistência face à complexa transformação e reinvenção do espaço educacional. Ao mesmo tempo em que traçamos algumas experiências que já vêm sendo desenvolvidas e que dão força para pensar o corpo.

Os escritos de Michel Foucault (1989), Gilles Deleuze e Félix Guattari (1995), Giorgio Agamben (2014-2017) e Baruch de Espinosa (1988), Preve e Corrêa (s/a) contribuíram para pensarmos conceitos teóricos, de modo a alargar a compreensão sobre possíveis problematizações e tensionamentos diante da potência criativa, crítica, performativa e política do corpo no âmbito educacional.

Percebemos que a constituição de um corpo-potência na educação, se faz possível por meio de enunciações e agenciamentos que nos encaminham a práticas e pensamentos que apresentam meios de transformação de ações, gestos, movimentos e dispositivos. Construir estratégias performativas, atuantes e ligadas ao âmbito do real, se apresentam como perspectivas possíveis, para refletir a inoperosidade de dispositivos e normativas, encaminhando fluxos experimentais que possam redimensionar o corpo e toda sua potência ativa no processo de escolarização.

Acreditamos que as propostas apresentadas pela Pedagogia Crítico-Performativa e pelo NAT, são linhas com relevo que potencializam ações, reverberando caminhos outros sobre a educação e práticas corporais que possam reinventar o espaço educacional. Promovendo, assim, a libertação de forças genuínas que afetam o corpo, aquelas mesmas que o constituíram, mas que também constituem mudanças e permitem compor e inventar o mundo e os modos de ser e viver.

Por fim, nos aproximamos novamente, das palavras da Edith Derdyk (2010), que muito atravessam esta nossa experiência de costura, escrita, costurar e escrever:

Escrevo como costuro. Costurando, ligando, furando, recortando pensamentos e tudo mais [...] Costurar não apenas como um procedimento construtivo. 
Além de furar e cortar, ligar é condição. Estabelecimento de vínculos entre dois furos: frente e trás, antes e depois, passado e futuro, memória e projeção. O vínculo é a ponte, a linha que liga o que é. Costurar seria então a afirmação do instante que se faz presente (s.p).

É nessa costura que pensamos educação para além da escolarização. De uma noção de educação que só se faz possível por meio da disciplinarização dos corpos, do controle de condutas e saberes disciplinarmente organizados. É com esse propósito que pensamos o corpopotência enquanto corpo ativo. Enquanto força que opera para produção de um ser humano mais ético e menos fragmentado, mais implicado e menos indiferente.

Por fim, não buscamos com esta escrita realizar julgamentos morais diante do processo de escolarização do ocidente. Longe disso, nos propomos a pensar esta processualidade para invitar e apresentar outras maneiras de ser, fazer e sentir a prática educacional. Acreditamos que por meio de encontros e costuras, olhares estagnados podem ser movimentados pela potência política e performativa da diversidade dos corpos e das singularidades, compreendendo a educação como ato ético e poético diante da complexidade das formas de vida.

Figura 05 - Charge de Rafael Correa.

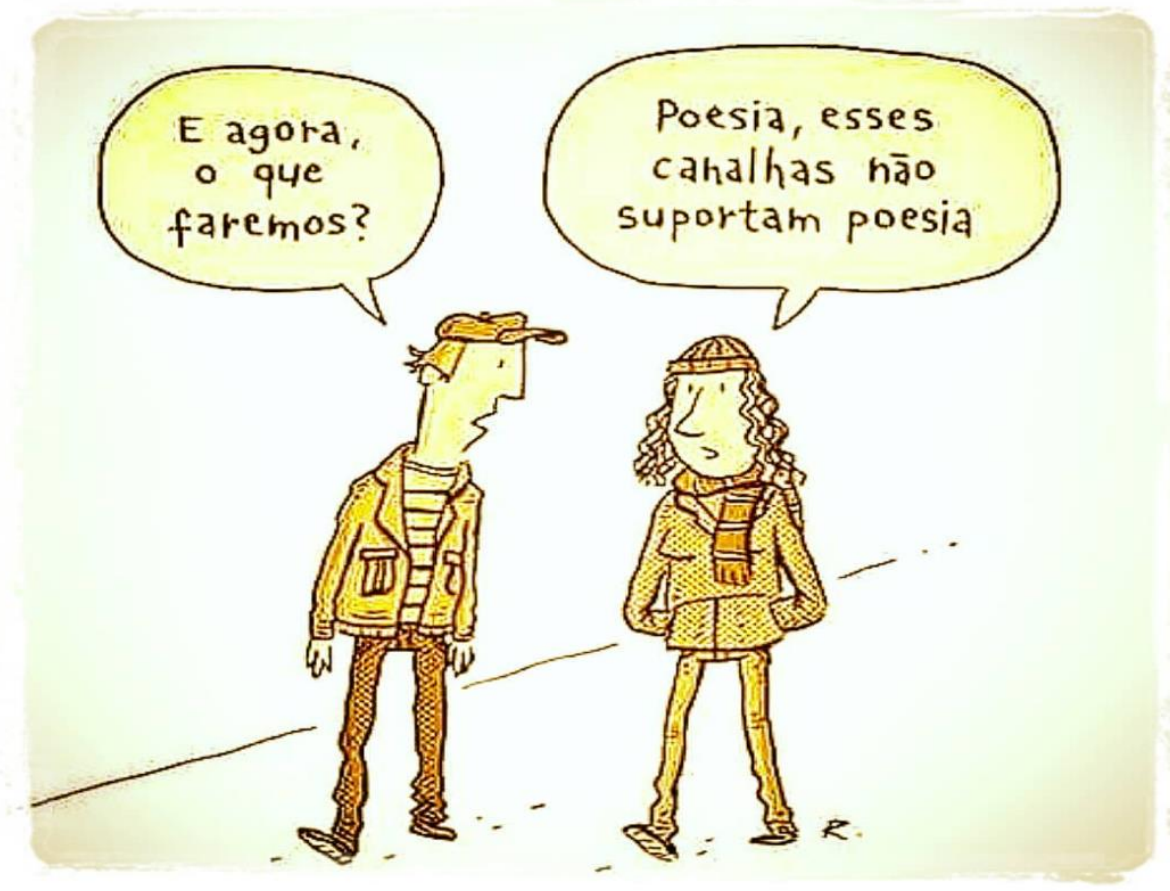

Fonte: https://almanaquedomalu.blogspot.com/2018/10/poesia-contra-hipocrisia-sempre.html 


\section{REFERÊNCIAS}

AGAMBEN, Giorgio. O amigo \& o que é um dispositivo? Trad. Vinícios Machado NicastroHonesko. Chapecó: Ed. Argos, 2014.

AGAMBEN Giorgio. Meios sem fim: notas sobre a política. Trad. Antonio Guerreiro. Belo Horizonte: Ed. Autêntica, 2017.

CASTELO BRANCO, Guilherme. Michel Foucault: filosofia e biopolítica. Belo Horizonte: Autêntica Editora, 2015.

CHAUÍ, Marilena. Espinosa: uma filosofia da liberdade. São Paulo: Editora Moderna, 1995.

CHAUÍ, Marilena. Espinosa: poder e liberdade. IN: Filosofia política moderna. De Hobbes a Marx. Boron, Atilio A. CLACSO, Conselho Latinoamericano de Ciências Sociais; DCPFFLCH, Departamento de Ciências Políticas, Faculdade de Filosofia Letras e Ciências Humanas, USP, Universidade de Sao Paulo, 2006.

CORRÊA, Guilherme Carlos. Educação comunicação anarquista: procedências da sociedade de controle no Brasil. São Paulo: Cortez Editora, 2006.

CORRÊA, Guilherme Carlos; PREVE, Ana Maria Hoepers. A educação e a maquinaria escolar: produção de subjetividades, biopolítica e fugas. Revista de Estudos Universitários, v. 37, n. 2, p. 181-202, 2011.

DELEUZE, Gilles; GUATTARI, Félix. O que é a filosofia? São Paulo: Imago, 1995.

DELEUZE, Gilles; PARNET, Claire. Diálogos. Paris: Flammarion, 1996.

ESPINOZA, Benedictus de Baruch. Ética. Tradução: Bernard Pautrat. Editora: Bilingue. 1988.

FOUCAULT, M. História da sexualidade: a vontade de saber. Rio de Janeiro: Edições Graal.

Vigiar e punir. Petrópolis: Vozes, 1989.

FOUCAULT, M. Outros espaços. In: MOTTA, M.B. (Org.). Ditos e escritos. Estética: literatura e pintura, música e cinema. Rio de Janeiro: Forense Universitária, v.III, p.411422, 2001.

FREUD, Sigmund. O infamiliar [Das unheimliche] (1919). Tradução Ernani Chaves e Pedro Helidoro Tavares. Belo Horizonte: Autêntica Editora, 2019.

GIL, José. Metamorfoses do Corpo. Tradução de Maria Cristina Meneses. Lisboa, 1980. 
GLUSBERG, Jorge. A Arte da Performance. São Paulo: Perspectiva, 1986.

ICLE, Gilberto. Da Performance na educação: perspectivas para a pesquisa e a prática. In: PEREIRA, Marcelo de Andrade (Org). Performance e Educação: (des)territorializações pedagógicas. Santa Maria: Ed. da UFSM, 2013.

JAQUET, Chantal. A unidade do corpo e da mente: afetos, ações e paixões em Espinosa. Tradução Marcos Ferreira de Paula e Luís César Guimarães Oliva. Belo Horizonte: Autêntica Editora, 2004.

OLY PEY, Maria. Oficina como modalidade educativa. Perspectiva: Florianópolis, v. 15, n. 27, p. 35-63, jan./jun. 1997.Paris: Seuil, 1988.

PACHECO, Elizabeth Medeiros et. al. Água Furtada. Revista Vazantes: Ceará,. v. 2, n. 2, p. 229-242, 2018.

PASSETI, Edson. Segurança, confiança e tolerância comandos na sociedade de controle. São Paulo em perspectiva, 18(1): 151-160, 2004.

PEREIRA, Marcelo de Andrade. Pedagogia crítico-performativa: tensionamentos entre o próprio e o comum no espaço-tempo escolar. cad. cedes [online], vol.37, n.101, p.29-44, 2017.

PREVE, Ana Maria Hoepers; CORRÊA, Guilherme Carlos. Tudo passa pelo corpo.

Motrivivência - Revista de Educação Física, Esporte e Lazer (UFSC), n. 15, 2000.

ROUDINESCO, Elisabeth; PLON, Michel. Dicionário de psicanálise. Rio de Janeiro: Jorge Zahar, 1998.

SANTOS, Amarildo Inácio dos; CERVI, Gicele Maria. Sujeitos (in)visíveis: corpos que pesam, vidas que pulsam na escola. Revista Cocar: Belém, v. 13, n. 25, p. 483-505, jan./abr. 2019.

\footnotetext{
i Graduação em Psicologia pela Universidade Regional Integrada do Alto Uruguai e das Missões- URI Santiago (2015), Mestrado em Artes Visuais pelo Programa de Pós-Graduação em Artes Visuais da Universidade Federal de Santa Maria (PPGART/UFSM) na Linha de Pesquisa Arte e Visualidade (2017). Atualmente é Doutoranda pelo Programa de Pós-Graduação em Educação da Universidade Federal de Santa Maria (PPGE/UFSM) na Linha de Pesquisa Educação e Artes. ORCID 0000-0001-8305-1476. E-mail: anamalavolta@gmail.com. Santiago/tRS.

ii Licenciatura em Química pelo Instituto Federal Farroupilha (2015), Mestrado em Educação pelo Programa de Pós-Graduação em Educação (PPGE) da Universidade Federal de Santa Maria (UFSM) (2017). Atualmente é Doutoranda em Educação pelo PPGE/UFSM e bolsista Demanda Social CAPES (com dedicação exclusiva). ORCID 0000-0003-2403-7513. E-mail: fernanda_rigue@ hotmail.com . Santa Maria/RS.

iii Graduação em Psicologia pelo Centro Universitário Franciscano (UNIFRA-2009), Mestrado em Psicologia Clínica pela Universidade do Vale do Rio dos Sinos - UNISINOS e Doutorado em Linguística pela Universidade Federal de Santa Maria - UFSM. Atualmente realiza pós-doutorado (PNPD - CAPES) no Programa de PósGraduação em Psicologia Universidade Federal de Santa Maria - UFSM. Docente no Curso de Psicologia da URI
} 
- Universidade Regional Integrada do Alto Uruguai e das Missões. ORCID 0000-0002-9604-1274. E-mail: camillabiazus@yahoo.com.br. Santa Maria/RS.

${ }^{4}$ Versos da música “Socorro”, composta por Alice Ruiz e Arnaldo Antunes, presente no álbum “Um som” (1998).

https://www.camara.leg.br/proposicoesWeb/prop_mostrarintegra?codteor=1707037\&filename=PL+246/2019

${ }^{6}$ Para maiores informações acerca do projeto, acessar o link: https://www.programaescolasempartido.org/projeto 